\title{
Plate Tectonics and Earthquake Potential of Spreading Ridges and Oceanic Transform Faults
}

\author{
Peter Bird, Yan Y. Kagan, and David D. Jackson \\ Department of Earth and Space Sciences, University of California, Los Angeles, California
}

\begin{abstract}
We use the Harvard CMT catalog to separate ocean-ridge seismicity into spreading and transform sub-catalogs. We use the tapered Gutenberg-Richter distribution to estimate the total seismic moment rates of plate-boundary zones from limited catalogs of large events. We present the plate boundary model PB1999 and use it to associate marine earthquakes with particular plate boundary segments. We then combine these tools to estimate corner magnitudes $\left(m_{\mathrm{c}}\right)$, spectral slopes $(\beta)$, and coupled lithosphere thicknesses for all spreading ridges and oceanic transform faults. The distribution of spreading earthquakes is consistent with "normal" $\beta=2 / 3$ (although $\beta$ is not well constrained) and with uniform $m_{\mathrm{c}}=5.8$. Coupled lithosphere thickness along ridges decreases quasi-exponentially (from about $500 \mathrm{~m}$ to under $50 \mathrm{~m}$ ) as spreading rate increases. Oceanic transform faults also have "normal" $\beta \cong 2 / 3$, but their corner magnitudes decrease from about 7.1 to about 6.3 with increasing relative plate velocity. Oceanic transform faults also show a quasi-exponential decrease in coupled lithosphere thickness (from about $3000 \mathrm{~m}$ to about $300 \mathrm{~m}$ ) as relative plate velocity increases. Perhaps this is due to formation of serpentine along slow ridges and transforms and its absence from fast ridges and transforms. Spreading ridges and oceanic transform faults both have imperfect seismic coupling because: (i) all detailed local studies of seismogenic lithosphere thickness exceed our mean values for coupled thickness, and (ii) if coupling were perfect, and seismogenic lithosphere thickness were as small as our estimated coupled thickness, it would require unreasonable stress drops or rupture shapes to explain the moments of the largest earthquakes.
\end{abstract}

\section{INTRODUCTION}

Many approaches can be used to estimate seismic hazard, and we hope it will be beneficial to develop alternative global models for objective testing and comparison. Jackson and Kagan [1999] and Kagan and Jackson [2000] presented an optimized method for projecting historical seismicity into the future as a distribution of seismic hazard which is spatially continuous. Their method is purely

Plate Boundary Zones

Geodynamics Series 30

Copyright 2002 by the American Geophysical Union

10.1029/030GD12 empiro-statistical, and does not require any knowledge of the structure and dynamics of the Earth. A second popular approach is to focus on the seismicity which is concentrated in the discrete curvilinear plate boundaries of a platetectonic model of the Earth's lithosphere. In principle, there should be a proportionality between some measure(s) of long-term-average seismicity and the relative velocity of the adjacent plates. However, it is necessary to consider that different types of plate boundaries have different structures, resulting in different proportionality factors. These factors may also be velocity-dependent. An additional complication is that seismicity in any local region is probably time-dependent, so the available seismic catalogs are not adequate to estimate long-term-average seismicity of most local regions. 
Our approach in this project is to mitigate the complication of time-dependence by averaging seismicity over as much length of plate boundary as possible within a certain plate-boundary class (spreading ridge, oceanic transform, subduction zone, or continental). We should then be able to empirically determine the parameters controlling the proportionality between plate velocity and average seismicity with reasonable precision. This is essential for getting an accurate view of the role of earthquakes in Earth dynamics, and should help to settle questions that have arisen about whether earthquake distributions in different kinds of plate boundaries have different corner magnitudes and/or spectral slopes. Although the practical seismic hazard from sea-floor spreading is minimal (except in Iceland and Afar), these questions come up over and over again in the hazard literature concerning continental regions.

This paper concerns the first two plate-boundary classes: spreading ridges and oceanic transform faults. Global surveys of mid-ocean seismicity have previously been published by Burr and Solomon [1978] and Solomon and Burr [1979], by Frohlich and Apperson [1992], and by Sobolev and Rundquist [1999]. We hope to present more definitive results by using a better plate model, a better frequency-magnitude distribution, and a seismic catalog which is more homogenous and comprehensive than that available to Solomon and Burr, and twice as long as the one available to Frohlich and Apperson. We do not use any moments estimated from body-wave magnitudes, although Sobolev and Rundquist [1999] did. In the end, we find that many previous conclusions are confirmed. However, we do not attempt to test published suggestions about stress drops for oceanic events, because the necessary constraints on the vertical extent of ruptures are not available on a consistent basis.

\section{DEFINITIONS}

The natural way to connect plate tectonics to seismicity is to predict long-term-average seismic moment rates for plate boundary regions. At any point on the boundary between plates $i$ and $j$, the horizontal part of the relative plate velocity is $\vec{v}_{i j}=\vec{\Omega}_{i j} \times \vec{r}$, where $\vec{\Omega}_{i j}$ is the relative angular velocity vector (Euler vector) for this pair of plates and $\vec{r}$ is the location vector measured from the center of the Earth, which is approximated as spherical. The area of one segment of the seismogenic plate boundary can be expressed as $\ell z \operatorname{cosec}(\theta)$, where $\ell$ is the length (measured along the fault trace), $z$ is the seismogenic lithosphere thickness, and $\theta$ is the dip of the plate boundary fault.
Specifically, we define seismogenic lithosphere thickness as measured vertically from the sea floor to the midpoint of the brittle/ductile transition (either in crust or mantle) which limits seismic ruptures. By the midpoint of the brittle/ductile transition, we mean the depth at which half of the relative plate motion is taken up by high-temperature ductile processes such as dislocation creep. (There will be some seismic slip below this depth, and some dislocation creep above this depth, but to first order we expect these to offset each other.)

Within the seismogenic lithosphere, some fraction $0 \leq c \leq 1$ of the frictional slip takes place during earthquakes (while the remainder takes place as aseismic frictional sliding); $c$ is usually referred to as the "seismic coupling", so we will refer to the product $c z$ as the "coupled thickness" of the seismogenic lithosphere. We emphasize that coupled thickness (an abstract average property of the whole plate boundary) is conceptually distinct from seismogenic lithosphere thickness (a local property that can be estimated following great earthquakes), and that numerically it may be either equal, or less.

If a horizontal unit vector $\hat{b}$ is used to describe the local strike of the plate boundary fault, and the relative plate velocity is partitioned into a parallel component ( $v_{\mathrm{p}}=\vec{v}_{i j} \cdot \hat{b}$, using the scalar product) and an orthogonal component $\left(v_{\mathrm{o}}=\left\|\vec{v}_{i j} \times \hat{b}\right\|\right.$, using the size of the vector product), then the plate-tectonic prediction of the area integral of seismic slip for this plate boundary segment would be

$$
\iint s \mathrm{~d} a=c z \ell \operatorname{cosec}(\theta)\left(v_{\mathrm{p}}+v_{\mathrm{o}} \sec \theta\right) \Delta t
$$

where $s$ is seismic slip, $\mathrm{d} a$ is an increment of the area of integration, and $\Delta t$ is any time interval.

The standard seismological model of a tectonic earthquake is that the fault surface is planar and that slip vectors are nearly parallel across the active surface. In this case, the seismic moment tensor will have a double-couple form, and the scalar seismic moment will be $M=\mu \iint s \mathrm{~d} a$, where $\mu$ is the elastic shear modulus. Over a sufficiently long time, the mean rate of elastic strain in the lithosphere should approach zero, and all the relative plate motion at depths less than $z$ should be expressed as earthquakes or as aseismic frictional sliding. Therefore, we can equate these two measures of moment rate, provided that we insert a factor $R$ to represent the imperfect recording of earthquakes: 


$$
\begin{aligned}
& \frac{1}{R} \lim _{\Delta t \rightarrow \infty} \frac{\sum M}{\Delta t}=\mu c \iint \dot{s} \mathrm{~d} a= \\
& \mu c z \ell \operatorname{cosec}(\theta)\left(v_{\mathrm{p}}+v_{\mathrm{o}} \sec \theta\right)
\end{aligned}
$$

where $\sum M$ means the sum of moments recorded during a time interval of length $\Delta t$.

The "recording factor" $R$ is a dimensionless number, normally less than unity, which is the ratio of the scalar seismic moment recorded in a particular catalog to the total scalar seismic moment produced in the Earth. In order to estimate $R$ we require assumptions about the form of the frequency-moment (or frequency-magnitude) relation for earthquakes.

In this study we use the tapered Gutenberg-Richter distribution [Jackson and Kagan, 1999; Kagan and Jackson, 2000], in which

$$
G\left(M, M_{\mathrm{t}}, M_{\mathrm{c}}\right)=\left(\frac{M}{M_{\mathrm{t}}}\right)^{-\beta} \exp \left(\frac{M_{\mathrm{t}}-M}{M_{\mathrm{c}}}\right)
$$

where $G$ is the fraction of earthquakes (by event count) in the catalog with moment exceeding $M, M_{\mathrm{t}}$ is the lower threshold moment for the catalog (which should be at or above the completeness limit), $\beta$ is the spectral slope, and $M_{\mathrm{c}}$ is the "corner moment". For convenience, we will often discuss moment magnitudes $m \equiv(2 / 3)\left(\log _{10} M-9.05\right)$ [Hanks and Kanamori, 1979], so there is also a "corner magnitude" $m_{\mathrm{c}}$ associated with $M_{\mathrm{c}}$, and there is a "threshold magnitude" $m_{\mathrm{t}}$ associated with $M_{\mathrm{t}}$. The concept of corner magnitude is critical because if this factor were not included, the total moment of all non-empty earthquake distributions would be infinite, which is unphysical. (Graphical examples of tapered GutenbergRichter distributions in this paper will include Figures 6 and 10, below.)

\section{DATA}

In this study, we use the Harvard Centroid Moment Tensor (CMT) catalog [e.g., Dziewonski et al., 1981, 1999], which we believe to be complete for shallow earthquakes of

$m \geq 5.8$ in all cases, and for $m \geq 5.2$ in certain restricted cases. In the 22-year period which we studied (1 Jan. 197731 Dec. 1998) this catalog has 15,651 events, of which 11,824 are shallow $(\leq 70 \mathrm{~km})$.

By fitting tapered Gutenberg-Richter distributions to actual catalogs by maximum-likelihood methods, we find that $\beta$ is typically close to $2 / 3$ [Kagan et al., 1999; Bird et al., 2000]. Specifically, for all shallow earthquakes (including shallow subduction and continental events) in the complete part of the CMT catalog, $\beta=0.669 \pm 0.024$ and $m_{\mathrm{c}}=8.07_{-0.17}^{+0.32}$. The former is based on the1982-1999 part of the catalog which is complete above $m_{\mathrm{t}}=5.6$ (since a low threshold is more important for determining $\beta$ ), and the latter on the full 1977-1998 catalog with $m_{\mathrm{t}}=5.8$ (since a long catalog is more important for determining $\left.m_{\mathrm{c}}\right)$. Assuming that this value of $\beta$ would apply for lower values of $M_{\mathrm{t}}$ and $m_{\mathrm{t}}$ if recording were perfect, the ratio of recorded (catalog) seismicity to model (tapered GutenbergRichter) seismicity gives the fractions of shallow events of each moment and magnitude which CMT detects (upper part of Figure 1); call these fractions $D(M)$ and $D^{\prime}(m)$, respectively. Once $D(M)$ has been estimated for this particular network of instruments, one can assume a particular corner moment $M_{\mathrm{c}}$ and convolve its tapered

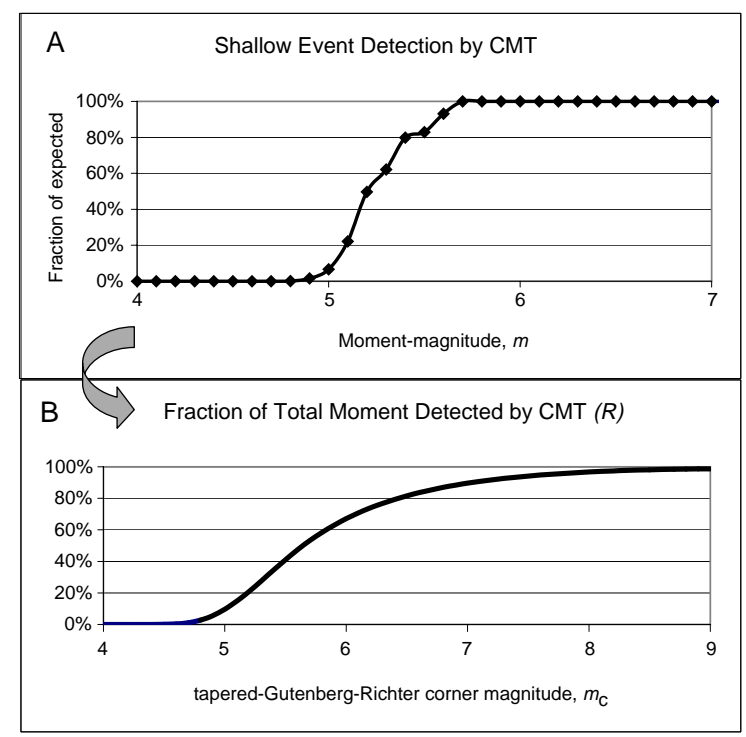

Figure 1. Estimated detection rates for shallow events in the Harvard CMT catalog. Part A (top), estimated fraction of events $D^{\prime}(m)$ detected at each magnitude. This was computed by fitting a tapered Gutenberg-Richter distribution (3) to all shallow events in the complete part of the catalog, and then assuming that the same parameters $\beta=0.669$ and $m_{\mathrm{c}}=8.07$ would describe the statistics of smaller events if detection were perfect. Part B (bottom), moment recording factors $R$ (fraction of actual scalar seismic moment expected to appear in the catalog) for various corner magnitudes $m_{\mathrm{c}}$, based on the upper part of the figure. 
Gutenberg-Richter distribution $G\left(M, M_{\mathrm{t}}, M_{\mathrm{c}}\right)$ with $D(M)$

to get the moment recording factor for shallow events located by the same network:

$$
R\left(M_{\mathrm{c}}\right)=\frac{\int_{0}^{\infty} M \frac{\partial G\left(M, M_{\mathrm{t}}, M_{\mathrm{c}}\right)}{\partial M} D(M) \mathrm{d} M}{\int_{0}^{\infty} M \frac{\partial G\left(M, M_{\mathrm{t}}, M_{\mathrm{c}}\right)}{\partial M} \mathrm{~d} M}
$$

(This is also shown in Figure 1B). We find that for $m_{\mathrm{c}} \geq 5.8$ (the lowest value proposed here), moment recording factor $R \geq 0.58$. Therefore, the correction for imperfect recording is important to include, but small errors in this factor are not likely to seriously contaminate our results.

Our plate tectonic model is based on the set of Euler vectors known as NUVEL-1A. DeMets et al. [1990] performed a global inversion to determine the relative rotation rates of the 12 largest plates (the NUVEL-1 model), and noted that published information also constrains the relative motions of the Philippine Sea and Juan de Fuca plates, to complete a global model. Then, DeMets et al. [1994] adjusted the rates of all the vectors to give the NUVEL-1A solution. However, neither reference specifies the locations of the plate boundaries, except implicitly in the list of plate-boundary data points.

To support this project, we have created a digital plateboundary model which we will refer to as PB1999. The basis for this model is the set of digitized boundaries created by the Paleo-Oceanographic Mapping Project (POMP) at the University of Texas. These boundaries, and a grid of digitized sea floor ages, were published by Mueller et al. [1997]. In areas of seafloor spreading with magnetic anomaly bands, our editorial changes were minor: (i) boundaries were brought together at common triplejunction points, and (ii) secondary propagating rifts on the east sides of the Easter and Juan Fernandez microplates were omitted. (From one point of view, the latter decision may cause the spreading rates for two of our normalfaulting earthquakes to be overstated by $10 \%$ and $18 \%$, respectively. From another point of view, local subdivision of plate boundaries into adjacent strands should not attempted without a consistent set of rules that can be applied globally.)

In oceanic regions without magnetic anomalies, subduction zones, and continental plate boundary zones, we manually selected many revised plate boundaries, using graphical software which allowed us to overlay:

a. gridded sea floor ages from POMP, with 6' resolution; b. gridded topography/bathymetry from ETOPO5 [Anonymous, 1988], with 5' resolution;

c. 1,511 subaerial volcano locations from the Smithsonian Institution's Global Volcanism Program [Simkin and Siebert, 1995];

d. 11,824 shallow earthquakes from the Harvard CMT catalog;

e. previous boundary selections from POMP or from Zoback [1992].

These were combined by giving highest priority to seafloor ages, second priority to topographic lineaments, and third priority to the principle that volcanism highlights extensional boundaries, but lies consistently $200 \mathrm{~km}$ to one side of subduction boundaries. Seismicity was used only in a few difficult cases (North America-South America boundary, India-Australia boundary) where plate boundaries have apparently jumped into former plate interiors. The resulting data set of about 3,700 boundary segments is available as file PB1999_boundaries.dig from http:// element.ess.ucla.edu/neotec/SHELLS/. In this file, special characters "/" and " $\mid "$ are used in the names of boundary segments to designate subduction zones (which are defined by Benioff zones of deep seismicity and/or volcanic arcs) and to show which plate is consumed; other plate boundaries are not categorized and are represented by names containing "-" (e.g., EU/PA vs. NA-EU).

\section{SPREADING RIDGES}

We define a "spreading ridge" as: (a) a plate-boundary segment from PB1999 with (b) a relative plate velocity based on NUVEL-1A that is divergent (specifically, the velocity vector is at least $45^{\circ}$ divergent from the boundary azimuth), and (c) location in seafloor with age known to be $<200$ Ma based on Mueller et al. [1997], and (d) not part of the anomalous India-Australia plate boundary (discussed below). With these selection criteria, the Earth has 53,008 $\mathrm{km}$ of spreading ridges (but not "more than 60,000 km" [Sobolev and Rundquist, 1999]). The length-weighted mean spreading rate is $48.8 \mathrm{~mm} / \mathrm{a}$, and the range of rates is from 1.1 to $151.2 \mathrm{~mm} / \mathrm{a}$ (Nazca-Pacific boundary at $32^{\circ} \mathrm{S}$ ).

Next, we define a "spreading earthquake" as (e) a shallow ( $\leq 70 \mathrm{~km}$ ) event from the Harvard CMT catalog of 1977-98 inclusive, with (f) the most-compressive principal axis of the moment tensor ( $\mathrm{P}$ axis) more vertical than either principal axis B or $\mathrm{T}$, and $(\mathrm{g})$ located no more than $63.7 \mathrm{~km}$ from a "spreading ridge" segment. This criteria yields 557 spreading earthquakes, with magnitudes of $4.85 \leq m \leq 6.35$. The sum of their scalar moments is $1.31 \times 10^{20} \mathrm{~N} \mathrm{~m}$. The largest event was on 1988.03.21, at 
$125.5^{\circ} \mathrm{E}, 77.6^{\circ} \mathrm{N}$ on the Eurasia-North America plate boundary.

Selection criterion (b) which permits oblique opening is intended to allow for inevitable errors in the azimuths of short plate boundary segments in PB1999, and also to permit all seafloor plate boundary segments to ultimately be classified as being either of spreading, transform, or subduction type. Selection criterion (f) concerning the orientation of the moment tensor was inspired by work of Frohlich [1992], Frohlich and Apperson [1992], and Frohlich [2001], who found that shallow earthquakes divide neatly into three groups with one of the three principal strain axes approximately vertical. Along mid-ocean ridges the division is particularly neat with $78 \%$ strike-slip, $17 \%$ normal, 2\% thrust, and 3\% "other" [Frohlich, 2001]. This is consistent with the theoretical expectation that one of the three principal stress axes should be vertical at shallow depths. Unlike them, we did not create a category labeled "odd" for events with all principal strain axes more than 30$40^{\circ}$ from vertical; this is because ultimately we hope to analyze all shallow seismicity using a very short list of plate-boundary categories. Our distance criterion (g) is intended to allow for finite width of central valleys on some ridges (10-15 km half-width), errors in PB1999 (unknown, but probably comparable), and errors in earthquake location (e.g., mean PDE/CMT discrepancies of $25 \mathrm{~km}$ or more [Smith and Ekström, 1997]). Solomon et al. [1988] studied ridges with spreading rates up to $44 \mathrm{~mm} / \mathrm{a}$, and found that all their normal-faulting earthquakes occured within the axial valleys, so lateral spread of epicenters is not a problem, at least along slow-spreading ridges. Our decision to exclude the India-Australia plate boundary was based on its lack of clear topographic signature, lack of Neogene magnetic anomaly bands, and anomalously large events (including one $m=7.67$ on 1983.11.30). This is probably a region in which extension has been too small to permit intrusion of asthenosphere and creation of new oceanic crust.

The global distribution of spreading earthquakes is shown in Figure 2. It is immediately apparent that this type of seismicity is not proportional to relative plate velocity, because slow-spreading ridges like the Mid-Atlantic Ridge have far more spreading earthquakes than the fast-spreading East Pacific Rise. Also, the largest earthquake in our spreading catalog took place on the slowest-spreading ridge segment, the Gakkel Ridge [Müller and Jokat, 2000]. Solomon [1976] was probably the first to discover the reduction in spreading seismicity with relative plate

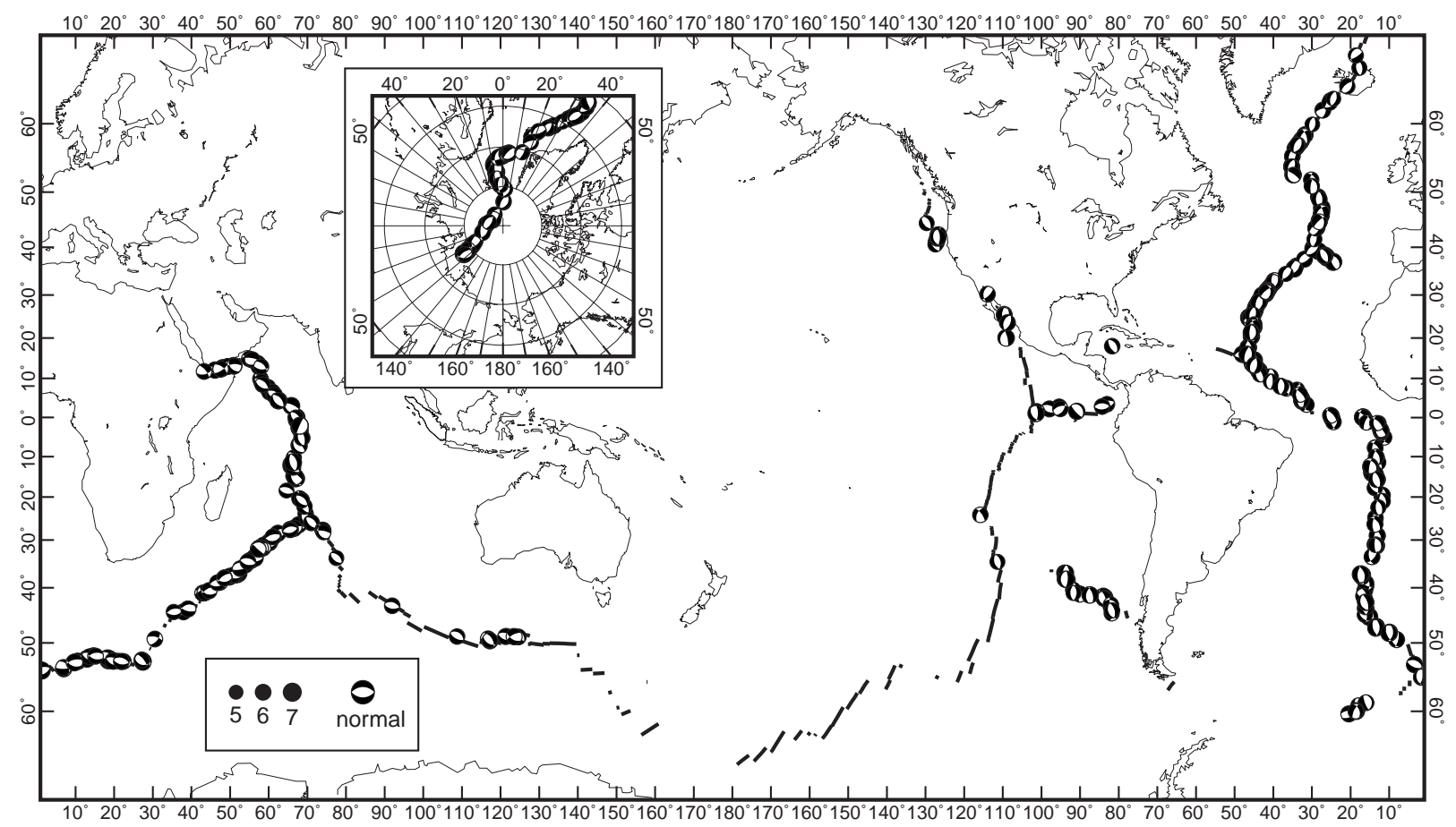

Figure 2. Global distribution of spreading ridges (heavy lines) and spreading earthquakes (beachballs), as defined in the text, during 1977-1998 inclusive, in the Harvard CMT catalog. Inset shows Arctic region. Beachballs show lower focal hemisphere projections of the double-couple part of the moment tensor. Note that the fast-spreading East Pacific Rise has very few spreading earthquakes, while the slow-spreading Mid-Atlantic Ridge has many. 

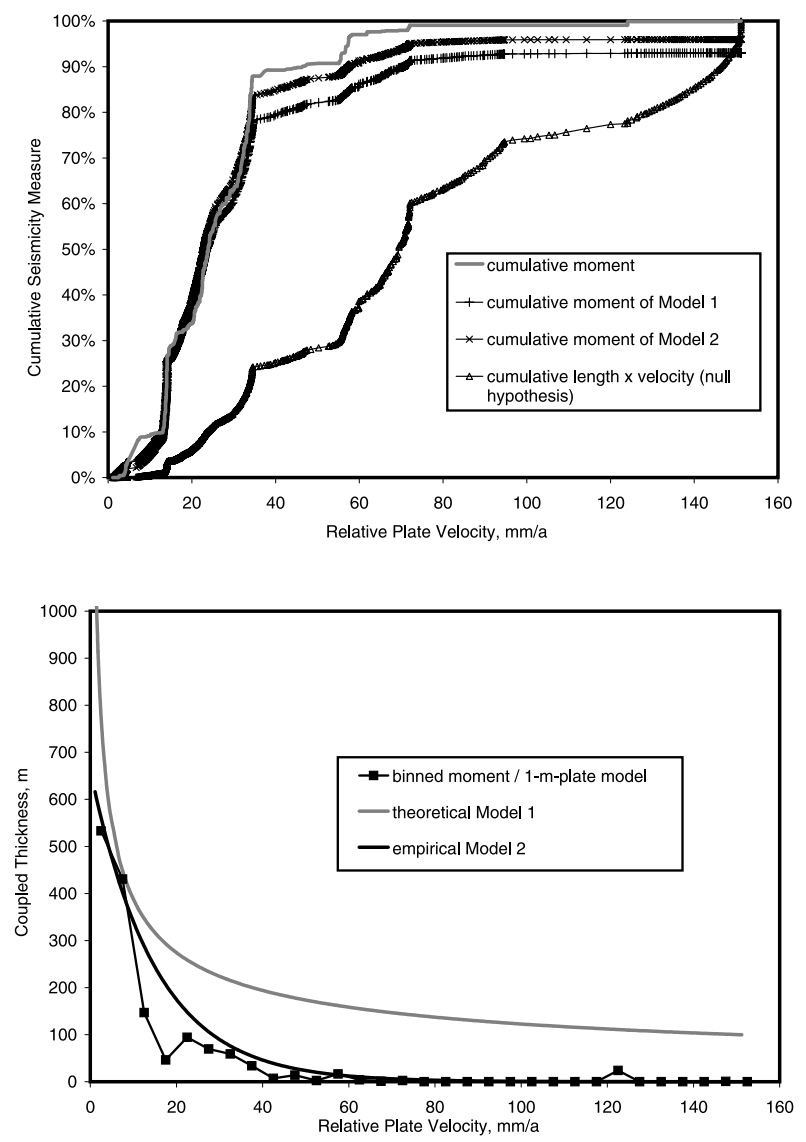

Figure 3. Cumulative (top) and differential (bottom) distributions of spreading earthquake moment as a function of relative plate velocity, and various models to explain them. The cumulative distribution is normalized to the total of $1.31 \times 10^{20} \mathrm{~N} \mathrm{~m}$ for the 22-year period. Differential (frequency histogram) distribution was created by binning earthquake moments into $5 \mathrm{~mm} / \mathrm{a}$-wide spreading-velocity bins, and then dividing these moment sums by the theoretical moment produced by a 1-m-thick lithosphere to get apparent coupled thickness. The null hypothesis is that all ridges have equal coupled thickness and produce moment in proportion to length $\times$ velocity, but this is clearly incorrect. Model 1 (self-similar) has coupled lithosphere thickness decreasing as inverse square root of velocity, and corner magnitude decreasing as $\log$ of velocity. Model 2 has constant corner magnitude, but an exponential decrease in coupled thickness with increasing velocity. Both models are corrected for imperfect moment detection, using the $R\left(m_{\mathrm{c}}\right)$ function from Figure 1B.

velocity (although he emphasized reduced earthquake size rather than frequency). Figure 3 presents our observation in quantitative form; we have sorted the spreading ridge segments by relative plate velocity, and then plotted both cumulative and differential (frequency histogram) scalar earthquake moment of segments against that expected in several models. The simplest model, or null hypothesis, would be that coupled thickness $(c z)$ and $\operatorname{dip}(\theta)$ are constant; in that case cumulative moment should vary with cumulative (length $\times$ velocity). However, the median (50\% cumulative level) for actual moment occurs at a spreading rate of $24 \mathrm{~mm} / \mathrm{a}$, which is much less than the median for (length $\times$ velocity) at $69 \mathrm{~mm} / \mathrm{a}$, and even less than the median for cumulative length at $34 \mathrm{~mm} / \mathrm{a}$. This discrepancy was also noted by Frohlich and Apperson [1992], who found that the ratio of actual moment production to expected moment production falls by two orders of magnitude from the slowest to the fastest ridges. They attributed this to the known variation of oceanic lithospheric thickness with age, which might imply some correlation with velocity as well.

The first model we tested (Model 1) for spreading ridge seismicity is that seismogenic lithosphere thickness $(z)$ is proportional to the inverse square root of relative plate velocity (v), while fault dip and seismic coupling are constant. Like Solomon [1976], we assume in this model that seismogenic lithosphere thickness is proportional to thermal lithosphere thickness and that spreading earthquakes are somehow constrained to take place at a constant distance, or within a constant distance, from the spreading center.

An additional feature of Model 1 is that corner magnitude should decrease with relative plate velocity in a particular way. Since we have assumed $z \sim v^{-1 / 2}$, the largest possible earthquake at a spreading center should have all physical dimensions scaled in proportion. Assuming constant aspect ratio, active fault area should scale as $v^{-1}$, while mean slip should scale as $v^{-1 / 2}$ (for constant stress drop). Jointly these relations imply a prediction that corner moment should vary as velocity to the $-(3 / 2)$ power: $M_{\mathrm{c}} \sim v^{-3 / 2}$. In that case, corner magnitude should vary as the common $\log$ of velocity: $m_{\mathrm{c}}=k-\log _{10}\left(v / 1 \mathrm{~mm} \mathrm{a}^{-1}\right)$, where $k$ is a constant.

Model 1 can be adjusted to give a good fit to the cumulative moment distribution, as shown in Figure 3. This fit was obtained by assuming constant $c=1$ and $\theta=45^{\circ}$, while adjusting $k$ and $z$; the result was that $k \cong 6.73$, and $z$ decreases from about $1227 \mathrm{~m}$ at $1 \mathrm{~mm} / \mathrm{a}$ to about $100 \mathrm{~m}$ at $152 \mathrm{~mm} / \mathrm{a}$. Under this model, the sharp fall-off in recorded events at relative velocities around 70 $\mathrm{mm} / \mathrm{a}$ is due to the corner magnitude falling below 4.85 , at which point the moment recording factor $R$ falls below 5\% (Figure 1).

A check of this prediction is seen in Figure 4, where we plot all spreading earthquake magnitudes against the Model 1 prediction of corner magnitude, using relative plate velocity as the ordinate. Unfortunately, about half 
of the recorded events fall above the Model 1 curve. In any tapered Gutenberg-Richter distribution, the corner magnitude is not an absolute limit, and some events should exceed it, but the fraction should be very small. Therefore, we conclude that Model 1 is not consistent with the data. In this, we disagree with Solomon [1976]; however, we have the benefit of 15 times as many events, which makes it possible for us to see that it is frequency of spreading earthquakes that decreases with spreading rate, rather than corner magnitude.

The best way to determine corner magnitudes empirically is to determine a threshold moment $M_{\mathrm{t}}$ for which the spreading earthquake catalog is complete, and then use the maximum-likelihood criterion to select the optimum parameters $\beta$ and $m_{\mathrm{c}}$ in a tapered GutenbergRichter distribution. (If $M_{\mathrm{t}}$ were set too low, then $\beta$ would be biased downward by failure to detect some small earthquakes. However, estimates of $M_{\mathrm{c}}$ and $m_{\mathrm{c}}$ are almost completely determined by the largest events in the catalog, and therefore are less sensitive to $M_{\mathrm{t}}$.) Stability of event counts over time is our criterion for completeness; for the whole period 1977-1998 there is completeness only for spreading earthquakes with $m \geq 5.4$, but if the time is restricted to 1982-1998, there appears to be completeness for $m \geq 5.2$. The maximumlikelihood criterion that we use is described in equation (12) of Kagan and Jackson [2000]; it provides 95\%confidence (or other) limits on each degree of freedom, and also a graphical display of the tradeoff between them (Figure 5). With the whole catalog, $\beta$ can be constrained (with $95 \%$ confidence) only as being in the range 0.56 to 1.00 , while $m_{\mathrm{c}}=5.82 \pm 0.07$ at $\beta=2 / 3$, with a slight trade-off between these two parameters: $\partial m_{\mathrm{c}} / \partial \beta=0.5$. For the period 1982-1998, we find slightly tighter constraints (Figure 5): $\beta=0.75 \pm 0.20 \quad$ and $m_{\mathrm{c}}=5.83 \pm 0.13$ with a similar trade-off $\partial m_{\mathrm{c}} / \partial \beta=0.7$. This result is consistent with the hypothesis of a universal $\beta=2 / 3$ [Kagan, 1999; Kagan et al., 1999; Bird et al., 2000]. The quality of the fit can be judged from Figure 6 , in which $\beta$ was set to $2 / 3$. Only the single largest event fails to fit, and this is off by only 0.2 magnitude units.

The previous results were for spreading earthquakes treated as a group. It is also important to check whether corner magnitude varies with plate velocity, as suggested by Solomon [1976]. However, we cannot divide the catalog into very many subsets because it is already so small. We chose to sort the spreading earthquakes by the relative plate velocity at their associated spreading ridges, and then to divide them into three sub-catalogs of roughly equal event count: spreading rate $0-18 \mathrm{~mm} / \mathrm{a}$, spreading rate $18-32 \mathrm{~mm} / \mathrm{a}$, and spreading rate $32-152 \mathrm{~mm} / \mathrm{a}$. The

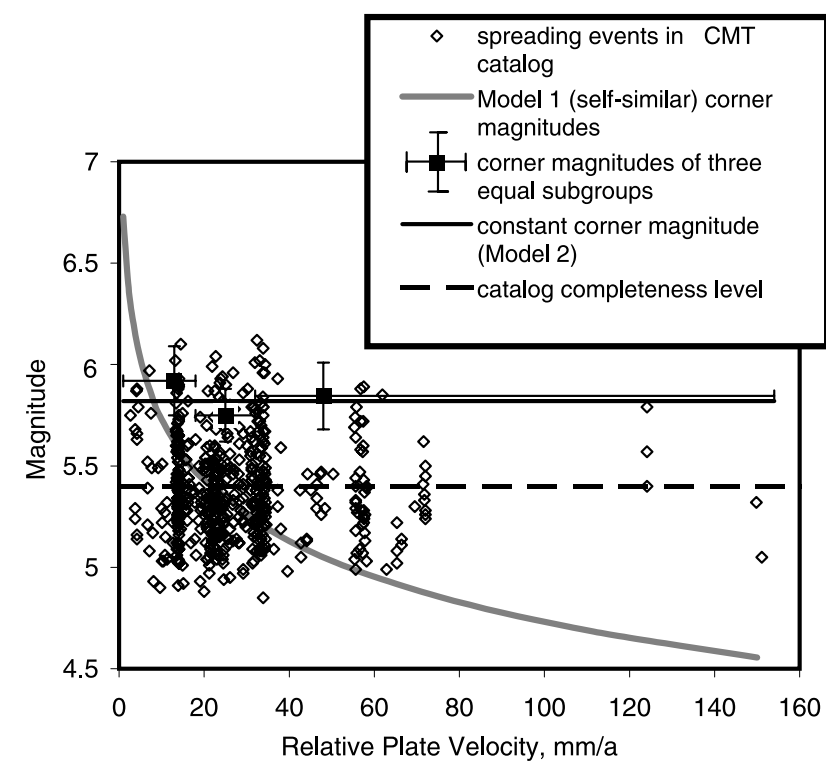

Figure 4. Spreading earthquake magnitudes versus relative plate velocity. The Model 1 curve has the predicted form $m_{\mathrm{c}}=6.73-\log _{10}\left(v / 1 \mathrm{mma}^{-1}\right)$, which can be rejected. Squares show maximum-likelihood corner magnitudes for three sub-catalogs of roughly equal size. All evidence seems consistent with a uniform corner magnitude of 5.82 for spreading earthquakes.

results of maximum-likelihood analysis were $m_{\mathrm{c}}=5.92 \pm 0.17, \quad 5.75 \pm 0.13, \quad$ and $5.85 \pm 0.17$, respectively (shown in Figure 4). These do not indicate any trend, and each is consistent with the group corner magnitude of 5.82 .

Model 2 for spreading ridges was developed by assuming uniform $m_{\mathrm{c}}=5.82$ (implying constant $R=0.58$ ), and assigning all of the variation of moment production with spreading rate to changes in the coupled thickness. By inspection of the differential (frequency histogram) results on apparent coupled thickness (Figure 3 ), it appears that a two-parameter exponential distribution model may be a reasonable empirical model:

$$
c z \cong d_{0} \exp \left(-v / v_{\mathrm{s}}\right)
$$

where $v_{\mathrm{S}}$ is the velocity scale for the exponential decay. (Solomon et al. [1988] showed a similar decelerating decline in seismogenic lithosphere thickness $(z)$ with velocity. Sobolev and Rundquist [1999] assumed that $z$ is known and inferred a decline in c.) One degree of freedom is fixed by the need to reproduce the total seismic moment of the spreading ridge catalog. The other has been adjusted to align the "model 2" and actual cumulative moment curves in the top part of Figure 3. 


\section{EARTHQUAKE POTENTIAL OF RIDGES AND TRANSFORMS}

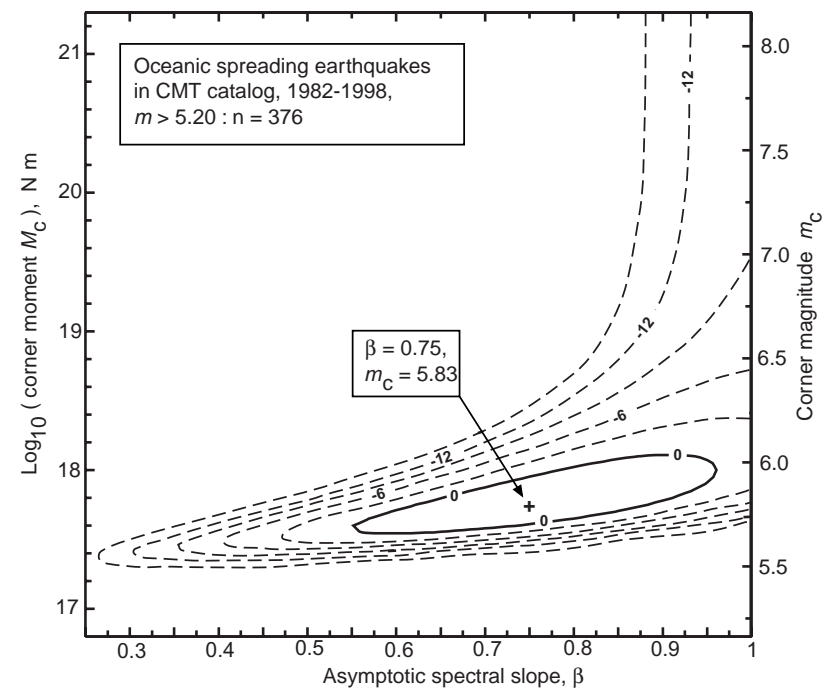

Figure 5. Maximum-likelihood determination of the tapered Gutenberg-Richter parameters $\beta$ and $m_{\mathrm{c}}$ for spreading earthquakes in 1982-1998 inclusive with $m \geq 5.2$. The method is described by equation (12) of Kagan and Jackson [2000]. Contours show parameter combinations of equal likelihood; the contour labeled " 0 " corresponds to $\chi^{2}(2)=-3$ and thus defines the $95 \%$ confidence region. Uncertainties stated in this paper are the horizontal and vertical dimensions of the region bounded by this contour.

The preferred parameters are $d_{0}=663 \pm 120 \mathrm{~m}$ and $v_{\mathrm{S}}=15 \pm 3 \mathrm{~mm} / \mathrm{a}$. These results are stated for assumed $\mu=49 \mathrm{GPa}$ and $\theta=45^{\circ}$, but they can easily be restated if other values are preferred. We used a dip of $45^{\circ}$ for three reasons: (i) this dip is found empirically at North Atlantic and Indian Ocean ridges [Huang et al., 1986; Huang and Solomon, 1987]; (ii) this dip maximizes the coupled thickness for fixed observed moment, and (iii) some recent studies have found evidence for low-angle detachment faulting at ridges [Mitchell et al., 1998], casting doubt on the universality of the $60-65^{\circ}$ dips that were traditionally assumed for normal faulting.

\section{OCEANIC TRANSFORM FAULTS}

We define an "oceanic transform fault" as: (a) a plateboundary segment from PB1999, (b) not previously identified as a subduction zone, with (c) relative plate velocity based on NUVEL-1A that is roughly parallel (specifically, the relative velocity vector is within $45^{\circ}$ of the fault strike), and (d) location in seafloor with age known to be <200 Ma based on Mueller et al. [1997], and (e) not part of the anomalous India-Australia plate boundary (discussed previously). With these selection criteria, the Earth has at least 506 oceanic transform faults (not 367 [Sobolev and Rundquist, 1999]) with total length of $44,433 \mathrm{~km}$. The length-weighted mean sliding velocity is $40.3 \mathrm{~mm} / \mathrm{a}$.

Next, we define an "oceanic transform earthquake" as (f) a shallow $(\leq 70 \mathrm{~km})$ event from the Harvard CMT catalog of 1977-98 inclusive, with $(\mathrm{g})$ the intermediate principal axis of the moment tensor (B axis) more vertical than either principal axis $\mathrm{P}$ or $\mathrm{T}$, and (h) located no more than $111 \mathrm{~km}$ from an "oceanic transform fault" segment. Notice that the distance criterion (h) is larger than the limit applied to spreading ridges. Test maps of events included and excluded with different distance limits showed this to be necessary; we think the reason may be that plate-boundary model PB1999 is lacking some very short transform segments. These criteria yield 1,335 oceanic transform earthquakes, with magnitudes of $5.00 \leq m \leq 7.39$. The sum of their scalar moments is $2.20 \times 10^{21} \mathrm{~N} \mathrm{~m}$ (which is 16.8 times greater than the sum for spreading earthquakes). The largest event was on 1987.09 .03 , at $158.3^{\circ} \mathrm{E}, 58.9^{\circ} \mathrm{S}$ on the Pacific-Australia plate boundary. Note that our selection criteria exclude the three $m>7$ events of 1987-88 in the Gulf of Alaska, and the $m=8.12$ Antarctic plate event of 1998.03.25 [Antolik et al., 2000], and the $m=8.06$ Macquarie Ridge event of 1989.05.23. The Gulf of Alaska and Antarctic plate events were intraplate earthquakes. The Macquarie Ridge event was a plate boundary event, but it occurred in lithosphere of unknown age which may be continental, and it was either in or immediately adjacent to a

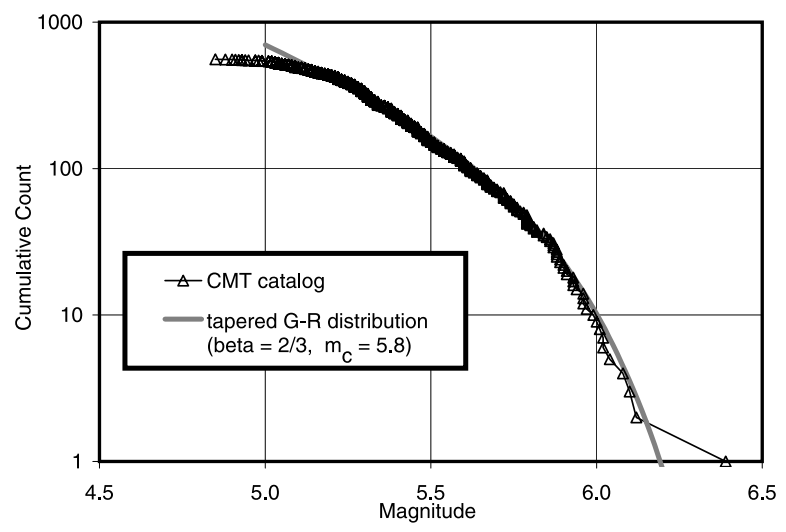

Figure 6. Fit of a tapered Gutenberg-Richter distribution (equation 3, with $\beta=2 / 3$ and $m_{\mathrm{c}}=5.8$ ) to the frequency-magnitude relation for spreading earthquakes in the Harvard CMT catalog, 1977-98. Since the corner magnitude is so close to the catalog threshold, no part of the distribution is free of the effects of the cornermagnitude term, and $\beta$ cannot be determined with high confidence. (However, it is less than the slope obtained by fitting a straight-line Gutenberg-Richter distribution.) 
subduction zone on the same plate boundary, and its lowfrequency mechanism had a thrust component [Ihmlé et al., 1993].

The global distribution of oceanic transform earthquakes is shown in Figure 7. This type of seismicity is also not proportional to relative plate velocity, because slow-spreading ridges like the Mid-Atlantic Ridge have about as many oceanic transform earthquakes as the fastspreading East Pacific Rise. Figure 8 presents this observation in quantitative form, using the same format as in Figure 3; we have sorted the oceanic transform segments by relative plate velocity, and then plotted cumulative and differential scalar earthquake moment of segments against that expected in several models. The simplest model, or null hypothesis, would be that coupled thickness $(c z)$ is constant; in that case cumulative moment should vary with cumulative (length $\times$ velocity). However, the median (50\% cumulative level) for actual moment occurs at a relative plate velocity of $34 \mathrm{~mm} / \mathrm{a}$, which is significantly less than the median for (length $x$ velocity) at $61 \mathrm{~mm} / \mathrm{a}$. This discrepancy was also previously noted by Frohlich and Apperson [1992], who concluded that the ratio of actual moment production to expected moment production falls by an order of magnitude from the slowest to the fastest transforms (but not by two orders of magnitude, as on spreading ridges).

Before fitting a tapered Gutenberg-Richter distribution, we studied catalog completeness and decided that CMT appears to be complete for oceanic transform events with $m \geq 5.5$ if the time window is restricted to $1982-1998$. In this range, maximum-likelihood analysis of oceanic transform earthquakes gives $\beta=0.69 \pm 0.08$ and $m_{\mathrm{c}}=6.90_{-0.17}^{+0.26} \quad(95 \%$-confidence limits). The smaller uncertainties result from the greater magnitude range between the catalog threshold and the corner magnitude, as compared to the previous case of spreading earthquakes (1.4 versus 0.6 ), and a greater number of events in the catalog. Again, the result for $\beta$ is consistent with the hypothesis of a universal $\beta=2 / 3$.

We also tested for strong variations of $\beta$ and/or $m_{\mathrm{c}}$ as functions of relative plate velocity, lithosphere age (specifically, the age of the younger plate at the midpoint of the transform), and transform fault length (specifically, total length between adjacent ridge or subduction segments, not the length of one digitization step). For each test, we divided the catalog into three sub-catalogs of roughly equal event count after sorting the earthquakes by

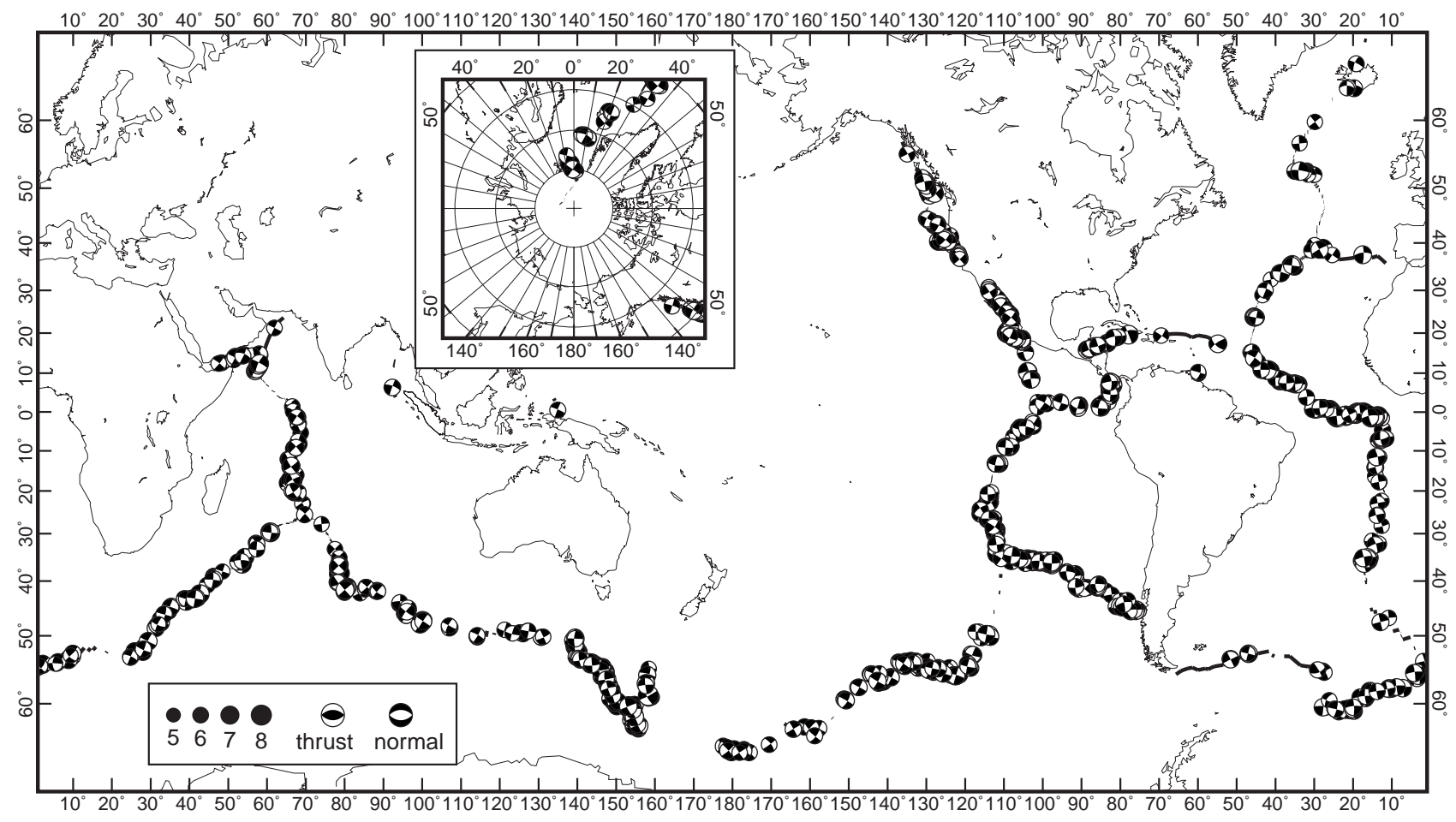

Figure 7. Global distribution of oceanic transform faults (heavy lines) and oceanic transform earthquakes (beachballs), as defined in the text, during 1977-1998 inclusive, in the Harvard CMT catalog. Inset shows Arctic region. Beachballs show lower focal hemisphere projections of the double-couple part of the moment tensor. 
their control parameter values. The clearest variation was obtained with relative plate velocity as the control parameter; like Burr and Solomon [1978] and Solomon and Burr [1979], we find that maximum oceanic transform earthquake size decreases with relative plate velocity. Corner magnitude is $7.06_{-0.23}^{+0.63}$ for velocities of
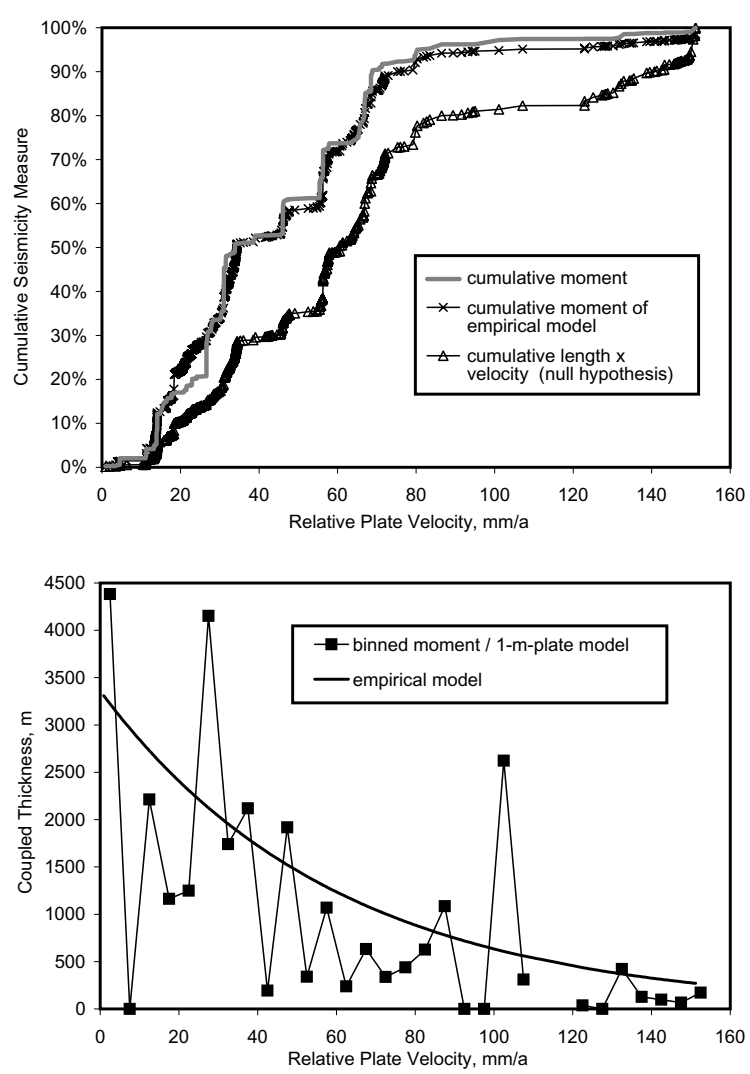

Figure 8. Cumulative (top) and differential (bottom) distributions of oceanic transform earthquake moment as a function of relative plate velocity, and two models to explain them. Cumulative curves are normalized to the total of $2.20 \times 10^{21} \mathrm{~N} \mathrm{~m}$ for the 22-year period. Differential (frequency histogram) distribution was created by binning earthquake moments into $5 \mathrm{~mm} / \mathrm{a}$-wide transform-velocity bins, and then dividing these moment sums by the theoretical moment produced by a 1-m-thick lithosphere to get apparent coupled thickness. The null hypothesis is that all transforms have equal coupled thickness and produce moment in proportion to length $\times$ velocity, but this is clearly incorrect. Our empirical model has corner magnitude declining slightly with increasing velocity, and an exponential decrease in coupled thickness with increasing velocity. Both models are corrected for imperfect moment detection, using the $R\left(m_{\mathrm{c}}\right)$ function from Figure 1B.
1-39 mm/a, $6.59_{-0.19}^{+0.30}$ for velocities of $39-67 \mathrm{~mm} / \mathrm{a}$, and $6.37_{-0.11}^{+0.21}$ for velocities of $67-152 \mathrm{~mm} / \mathrm{a}$. Note that the 95\%-confidence bounds for $m_{\mathrm{c}}$ of the fastest and the slowest group do not overlap. Figures 9 and 10 show this variation. Figure 9 also shows a quadratic function fit to the apparently monotonic variation of corner magnitude with velocity. The proposed form is:

$$
m_{\mathrm{c}}=7.43-\left(\frac{v}{55 \mathrm{~mm} \mathrm{a}^{-1}}\right)+\left(\frac{v}{131 \mathrm{~mm} \mathrm{a}^{-1}}\right)^{2}
$$

which passes through the three sub-group corner magnitudes, and is also guided by the $95^{\text {th }}$-percentile magnitudes of events in each of 6 roughly equal subgroups. (The $95^{\text {th }}$-percentile magnitude is not a substitute for a corner magnitude determined by maximumlikelihood, but it may provide additional confidence that the trend exists, since it is such a simple metric.)

The largest oceanic transform earthquake known was the 1942.11 .10 event with $M=(1.35 \pm 0.45) \times 10^{21} \mathrm{~N} \mathrm{~m}$ ( $m=8.05_{-0.12}^{+0.08}$ ) on the Southwest Indian Ocean Ridge [Okal and Stein, 1987]. This was not part of our data set, but it is natural to ask whether it fits. The relative plate velocity at this event is $14 \mathrm{~mm} / \mathrm{a}$, so our estimated corner magnitude would be 7.19. Using (3) with this corner magnitude, an oceanic transform earthquake of magnitude 8.05 should not occur in the age of the Earth. In order to raise the chance of such an earthquake to $50 \%$ per century, the corner magnitude would have to be increased to 7.76 , or the event magnitude reduced to 7.59. So, the event is inconsistent with our proposed corner magnitude. However, its moment was based on analog records at 3 distant stations within a narrow range of azimuths, and we can not give it the same confidence that we accord to moments in the CMT catalog. Also, increasing our corner magnitude to 7.76 would lead to a deficit of $m \geq 7$ events: 24 (expected) - 7 (observed) $=17$ missing in the 22-year period covered by CMT. We believe instead that special circumstances may have biased the moment determination for the 1942 event.

For $\beta$, we find no significant trend with velocity: $0.60 \pm 0.11$ at $1-39 \mathrm{~mm} / \mathrm{a}, 0.65 \pm 0.14$ at $39-67 \mathrm{~mm} / \mathrm{a}$, and $0.63 \pm 0.15$ at $67-152 \mathrm{~mm} / \mathrm{a}$. Our results appear very different from those of Langenhorst and Okal [1999], who reported variations of $\beta$ from 0.47 on slow oceanic transforms of the Southwest Indian Ocean Ridge to 1.5 on the fast transforms of the East Pacific Rise. Part of the discrepancy may be due to the larger formal errors on 


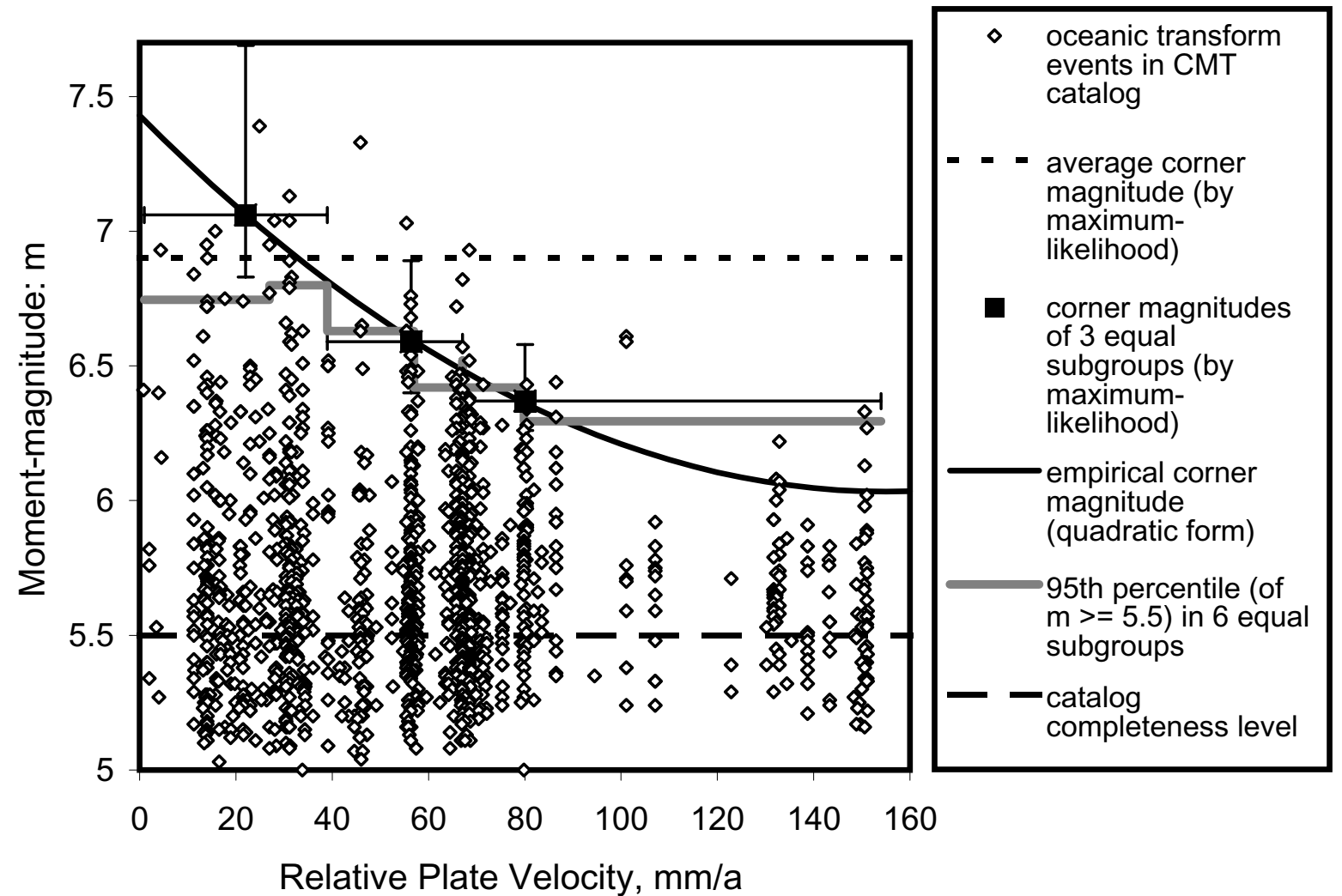

Figure 9. Magnitudes of oceanic transform earthquakes versus relative plate velocity. The catalog is only complete for $m>5.5$, and the corner magnitude for the whole group is 6.9. Corner magnitudes for three equalsized subgroups (squares) show an important reduction of corner magnitude with velocity. An empirical quadratic form has been fit to these values.

their $\beta$ values, which must follow inevitably from their smaller catalogs, which in turn result from their decision to split seismicity into regions instead of lumping it globally. However, it is also likely that some of the discrepancy is due to different assumptions about the frequency-magnitude distribution: Langenhorst and Okal [1999] assume a piecewise-linear frequency-magnitude law with a discrete change in slope, whereas we assume a tapered Gutenberg-Richter distribution with continuously increasing slope. Since transform earthquake catalogs (to date) provide only a limited spectral window between the threshold magnitude (about 5.5) and the corner magnitude (which we argue is from 6.0 to 7.4), we would assert that there is no part of the available frequency-magnitude distribution which is unaffected by the corner-magnitude term. According to this argument, the mean slope of any finite part of the distribution should be greater than $\beta$ (as the tapered Gutenberg-Richter distribution defines it).

This latter explanation also applies to the result of Okal and Romanowicz [1994] that strike-slip events on the mid-ocean ridge system have $\beta$ of 1.05. In their Figure $4(\mathrm{a})$, it is noticeable that frequency-magnitude distribution is convex, and that a straight-line model fits poorly. If a tapered Gutenberg-Richter distribution were applied, the convexity would be built-in (e.g., our Figure 10), and $\beta$ would be redefined as the asymptotic spectral slope at small moments, giving a lower value similar to ours.

Our result also differs from that of Kagan [1999], who obtained significantly higher $\beta$ values for oceanic earthquakes than for subduction and continental earthquakes. In his study, oceanic earthquakes were not separated into spreading and transform events, nor were transform events separated by relative plate velocity. Thus, populations with different corner magnitudes were inadvertently mixed, giving a distribution which had a complex form and artificially high spectral slope.

Solomon and Burr [1979] used the ratio of transform length to velocity as a proxy for lithospheric age, and suggested (on the basis on about 40 events) that increasing age is associated with larger events. When we attempt to analyze rigorously for possible effects of lithosphere age, we encounter a problem because $80 \%$ (by length) of oceanic transforms have midpoint ages (on the younger side) of $12 \mathrm{Ma}$ or less. Then, to divide the 


\section{EARTHQUAKE POTENTIAL OF RIDGES AND TRANSFORMS}

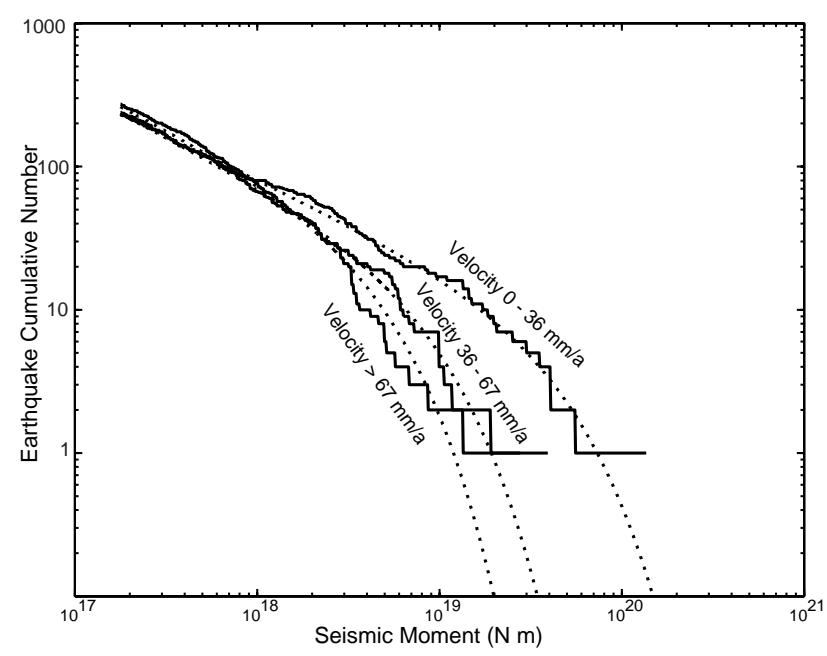

Figure 10. Fits of tapered Gutenberg-Richter frequencymoment distributions (equation (3); dotted curves) to the oceanic transform earthquake catalog, after division into three subgroups on the basis of relative plate velocity. Spectral slope $\beta$ is in the range $0.60-0.65$ for each curve, but corner magnitude $m_{\mathrm{c}}$ decreases from 7.06 to 6.59 to 6.37 as velocity increases.

transform seismic catalog into three equal-count populations we must use bins of 0-1.2 Ma, 1.2-5 Ma, and 5-180 Ma. The maximum-likelihood corner magnitudes are then $6.65_{-0.30}^{+\infty}, 6.47 \pm 0.15$, and $6.99_{-0.21}^{+0.47}$, respectively at $\beta$ values of $0.90_{-0.16}^{+0.10}, 0.56 \pm 0.14$, and $0.60 \pm 0.10$, respectively. We are concerned that small location errors in our PB1999 plate boundary model may combine with small errors in the gridded ages of Mueller et al. [1997] to produce both random and systematic age errors well over 1.2 Ma, which is the width of the first bin. Also, the distribution of transforms is not ideal in another way: all of the transforms with velocity over $60 \mathrm{~mm} / \mathrm{a}$ have midpoint ages under $5 \mathrm{Ma}$. Therefore, apparent effects of age could really be effects of velocity. Thus, we cannot demonstrate statistically that the possible effects of lithospheric age are real, and do not choose to build them into our model.

The third possible control parameter is transform length. (It is true that length is highly correlated with midpoint age times relative plate velocity, but the correlation is not perfect because not all transforms connect two ridge segments on the same plate boundary, and not all transforms are in steady-state.) To obtain roughly equal event counts in three sub-catalogs, we divide transform earthquakes according to the length of their associated transforms using categories of 0-140 km,
140-330, and 330-1650 km. The resulting maximumlikelihood results are $m_{\mathrm{c}}=6.63_{-0.23}^{+0.80}, 6.73_{-0.18}^{+0.38}$, and $7.00_{-0.24}^{+0.58}$ respectively, with $\beta=0.80_{-0.15}^{+0.20}, 0.63 \pm 0.11$, and $0.62 \pm 0.10$, respectively. There is a suggestion of a trend of increasing corner magnitude with length, but the confidence limits of the first and last categories overlap. Also, direct examination of all magnitudes as a function of transform length suggests that if there is such an trend, it is restricted to the range of lengths under $400 \mathrm{~km}$. (Burr and Solomon [1978] proposed a similar relationship, although theirs was influenced strongly by the anomalous 1942 event.) We are not convinced that the data supports transform length as an important control parameter, and do not choose to incorporate it into our model.

Our preferred model assumes constant $\beta=2 / 3$, dip $\theta=90^{\circ}$, and $\mu=49 \mathrm{GPa}$. It assumes that corner magnitude varies only with relative plate velocity, according to the empirical quadratic function (6). We assign all other variations of seismicity with relative plate velocity to changes in the coupled thickness, and express coupled thickness as a function of velocity by the same two-parameter exponential function (5) that was used for spreading ridges. As before, one degree of freedom is fixed by the total moment in the oceanic transform catalog, and the other is adjusted to fit the cumulative distribution of moment as a function of velocity (in the upper half of Figure 8): the results are $d_{0} \cong 3360 \pm 600 \mathrm{~m}$ and $v_{\mathrm{s}} \cong 60 \pm 10 \mathrm{~mm} / \mathrm{a}$. This gives coupled thickness declining from a maximum of about $3300 \mathrm{~m}$ at $1 \mathrm{~mm} / \mathrm{a}$ to a minimum of about $270 \mathrm{~m}$ at $151 \mathrm{~mm} / \mathrm{a}$. For comparison, Burr and Solomon [1978] and Solomon and Burr [1979] found "effective transform width" (a similar measure) of single events had great scatter, but the running mean of their results decreases with relative plate velocity, from about $2500 \mathrm{~m}$ to about $250 \mathrm{~m}$. This agreement is reassuring, as their study had no events in common with ours.

\section{DISCUSSION}

We based this project on the tapered Gutenberg-Richter distribution (3) instead of the traditional GutenbergRichter law (only the first right-hand term of (3)) for two reasons. First, the tapered distribution automatically yields a finite rate of moment production (if $\beta<1$ ), whereas the moment rate of the traditional law is infinite, unless it is arbitrarily truncated at some maximum moment and magnitude. Second, an absolute cut-off at a 
maximum magnitude can be falsified by a single future event, so in practice a maximum magnitude cannot be determined from real data. The tapered distribution predicts a gradual roll-off of seismicity, which allows statistical methods to provide bounded estimates of the corner magnitude from finite catalogs. What we have found is that both spreading earthquakes and oceanic transform earthquakes, if fit separately to a tapered Gutenberg-Richter distribution, are consistent with the "universal" value of $\beta=2 / 3$ [Kagan, 1999; Kagan et al., 1999; Bird et al., 2000]. The greater slopes of these distributions (compared to continental or subduction zone seismicity) result from the proximity of the catalog threshold to the corner magnitude, and do not necessarily imply variations of $\beta$, as they would in the traditional power-law distribution. This simple result should encourage routine use of the tapered Gutenberg-Richter distribution.

The corner magnitudes we have found are significantly less than those of subduction zones and continental regions (which are close to 8.1). The corner magnitude for spreading earthquakes is 5.8, apparently independent of the spreading velocity. (However, the number of recorded events with spreading rates over $80 \mathrm{~mm} / \mathrm{a}$ is very small, so future catalogs derived from ocean-bottom seismometer records may show some variation.) This small corner magnitude is consistent with a reduced size for spreading earthquake ruptures, which is enforced by the thin lithosphere around spreading centers. The corner magnitudes for oceanic transform earthquakes are intermediate (about 7.1 to 6.3), which can be explained by the fact that oceanic transform earthquakes typically occur in lithosphere that is older (and presumably thicker) than lithosphere at spreading rises, but not so old as lithosphere at most subduction zones or in continents.

The result that corner magnitude for oceanic transform earthquakes depends primarily on relative plate velocity agrees qualitatively with the previous independent study of Burr and Solomon [1978], but it is not easy to understand. We had expected stronger control by lithospheric age (which might limit the vertical extent of large ruptures) and/or by transform length (which might limit the horizontal extent of large ruptures). Perhaps the important variable factor is not fault area, but stress drop. It is plausible that stress drop should increase with healing time between earthquakes. Fast-moving transforms would have more frequent earthquakes, and allow less healing time between them, so they might be expected to have systematically smaller stress drops. If this were the primary cause, then stress drop should vary by a factor of 11 in order to explain our inferred variation of corner magnitude by 0.8 units (assuming constant rupture dimensions for the corner events). Unfortunately, it will be difficult to measure stress drops of submarine transform earthquakes in order to test this hypothesis; we would require either some form of seafloor geodesy, or at least a network of ocean-bottom seismometers permitting routine joint hypocentral determination of aftershocks. With either technology, the coverage would have to be nearly global to guarantee inclusion of the largest transform earthquakes.

Another surprise was that "coupled thickness" (the product of seismogenic lithosphere thickness and seismic coupling) decreases with increasing relative plate velocity for both spreading and oceanic transform earthquakes. For spreading, the velocity scale for the exponential decrease is $15 \pm 3 \mathrm{~mm} / \mathrm{a}$, but for oceanic transforms, it is $60 \pm 10 \mathrm{~mm} / \mathrm{a}$.

Yeats et al. [1997; page 171] point out that some oceanic transform faults cut lithosphere with thin crust or no crust at all. For example, the Gakkel Ridge in the Arctic (the site of our largest spreading earthquake) may be forming little or no oceanic crust [Coakley and Cochran, 1998; Müller and Jokat, 2000]. In such places, sea water can weather the mantle directly, forming serpentine (mostly lizardite). Most of the known cases of serpentine exposure along transform faults are on slowspreading ridge systems [e.g., Tucholke and Lin, 1994; Cannat et al., 1995]. Lizardite is weaker than other materials at low temperature due to a weak shear cleavage, but absolute strength is probably not relevant to the stick-slip/stable-sliding transition. Lizardite's critical property may be that it is relatively nondilatant [Escartin et al., 1997]. According to Sleep [1997], theoretical models of faults show that even a small amount of frictional dilatancy suffices to stabilize sliding and quench earthquakes. Therefore, the slow transforms with lizardite "lubrication" might paradoxically be more seismic, whereas fast and serpentine-free transforms with normal dilatancy could be sliding stably. An obvious objection to this model is that most continental transform faults are seismic, although it is not apparent that they are lubricated with serpentine.

Our methods cannot separate the seismic coupling $c$ from the seismogenic lithosphere thickness $z$. Fortunately, this is not necessary for seismic hazard estimation, since it is the product, coupled thickness, which determines the moment rate, and corner magnitudes can be determined empirically. However, local studies can often give accurate hypocentral depths or rupture dimensions, putting a lower limit on $z$ and thus an upper limit on $c$ : 


\section{EARTHQUAKE POTENTIAL OF RIDGES AND TRANSFORMS}

Huang et al. [1986] determined centroid depths for 14 normal-faulting events in the North Atlantic as 1.2-3.1 $\mathrm{km}$. (All depths quoted are measured from the sea floor.) They suggested that the vertical extent of ruptures is twice as large $(2.4-6.2 \mathrm{~km})$. At these spreading rates $(16-33$ $\mathrm{mm} / \mathrm{a}$ ) our coupled thickness estimates are 0.23 to $0.7 \mathrm{~km}$, respectively, so apparently coupling is less than $0.1=0.23 \mathrm{~km} / 2.4 \mathrm{~km}$.

Engeln et al. [1986] determined centroid depths and estimated rupture sizes for 40 large transform earthquakes in the Atlantic, concluding that the mean temperature limiting the extent of ruptures is $600^{\circ} \mathrm{C}$. When they assumed this to be a general rule for all parts of the 7 transforms which they studied, they concluded that only about $45 \%$ of the expected slip in the 60 -year period of their catalog was seismic. (This value of coupling is probably biased toward a high result because the transforms were chosen for their large earthquakes.)

Huang and Solomon [1987] determined centroid depths for normal-faulting events on the Northwest Indian Ocean ridge; they were $1-4 \mathrm{~km}$, so the vertical extent of ruptures was estimated to be $2-8 \mathrm{~km}$. At these spreading rates (22$44 \mathrm{~mm} / \mathrm{a}$ ) our coupled thickness estimates are 153 to 35 $\mathrm{m}$, respectively, so apparently coupling is less than $0.08=153 \mathrm{~m} / 2000 \mathrm{~m}$.

Solomon et al. [1988] summarized 50 normal-faulting events on ridges with spreading rates below $44 \mathrm{~mm} / \mathrm{a}$ (including many already discussed by Huang et al. [1986] or Huang and Solomon [1987]), and found that the maximum centroid depth decreases from 6 to $2 \mathrm{~km}$ as spreading rate increases. Assuming that the seismogenic lithosphere thickness is twice as large, they found that coupling is no more than $0.10-0.20$ in the axial valleys of slow-spreading ridges.

Bergman and Solomon [1988] studied 12 large earthquakes on transforms in the North Atlantic, and found that 5 of the ruptures had large vertical dimensions of 14-20 km. Considering our estimated coupled thicknesses at North Atlantic spreading velocities, this implies that seismic coupling on North Atlantic transforms is less than about $2100 \mathrm{~m} / 14000 \mathrm{~m}=0.15$.

Watanabe et al. [1992] used 18 ocean bottom seismometers to determine depths of 179 events on the Reykjanes ridge: the deepest was nominally at $12 \pm 5 \mathrm{~km}$. If we estimate that seismicity actually ends at about $8 \mathrm{~km}$, then this estimate of $z$ still greatly exceeds our value of coupled thickness $c z=0.19 \mathrm{~km}$ for this spreading rate, suggesting regional coupling of only 0.02 .

Sobolev and Rundquist [1999] divided the mid-ocean ridge system into 15 regional segments. Coupling on spreading ridges varies regionally from 0.003 to 0.1 if the seismogenic lithosphere thickness has the values estimated by Solomon et al. [1988]. Coupling on oceanic transform faults varies from 0.014 to 0.6 if the seismogenic lithosphere thickness extends down to the model $400^{\circ} \mathrm{C}$ isotherm.

Okal and Langenhorst [2000] found that seismic coupling on the Eltanin transform system is only 0.05 to 0.25 , with a mean of 0.10 .

Abercrombie and Ekström [2001] studied 14 large events on the Romanche and Chain transforms and found that the deepest ruptures extend to model temperatures of $600^{\circ} \mathrm{C}$.

We only know of two local studies consistent with perfect coupling $(c=1)$. Brune [1968] found that the Romanche transform system (a group of 5 adjacent transform faults) was fully coupled during 1920-1952 if the seismogenic lithosphere thickness is $z=6.1 \mathrm{~km}$ and the elastic shear modulus is $\mu=33 \mathrm{GPa}$. The Harvard CMT catalog for 1977-1998 confirms this by yielding $c z$ $=8.7 \mathrm{~km}$ if the same $\mu$ is assumed. Kanamori and Stewart [1976] determined the moments of the 1967 and 1974 events on the Gibbs fracture zone, and used its entire seismic history to suggest a 13 -year recurrence time for such events. Their results are consistent with perfect coupling if $z=10 \mathrm{~km}$ and $\mu=42 \mathrm{GPa}$. However, during the period of the Harvard CMT catalog, the moment rate of the Gibbs fracture zone has only been $32 \%$ of their rate; seismogenic lithosphere thickness could not have changed, therefore apparent coupling has fallen to only 0.32 (using the same parameters). As interesting as these comparisons are, we believe that no seismic catalog is yet long and accurate enough to determine coupling on a single transform fault with acceptable accuracy. (One can infer this from the large scatter of coupled thickness values in the lower part of our Figure 8 , because any individual transform fault falls entirely within one bin.) The two cases of apparent perfect coupling could just be extremes of a normal distribution caused by finite-time effects. That is why we emphasize global averages in our approach.

We can also make a global argument that $c$ is small by assuming maximum values for certain source parameters. For the largest spreading earthquakes, let the elastic modulus be $49 \mathrm{GPa}$, fault dip $45^{\circ}$, aspect ratio (length/width) of the rupture no more than 20, and stress drop no more than $10 \mathrm{MPa}$ [Richardson and Solomon, 1977]. Then, it should require vertical rupture dimensions $z>2125 \mathrm{~m}$ to generate events as large as $M=1.29 \times 10^{18} \mathrm{~N} \mathrm{~m}(m=6.04)$, of which there are 5 in our spreading earthquake catalog. Since our coupled thicknesses for spreading rises range from $600 \mathrm{~m}$ down to much smaller values, it seems necessary that $c$ is less than 
0.28 on slow-spreading ridges, and much lower on fastspreading ridges.

For the largest oceanic transform earthquakes, assume the same parameters except for a fault dip of $90^{\circ}$. Then, it should require vertical rupture dimensions $z>5100 \mathrm{~m}$ to generate events as large as $M=4.09 \times 10^{19} \mathrm{~N} \mathrm{~m}$ $(m=7.04)$, of which there are 4 in our oceanic transform catalog. Since our model coupled thicknesses for oceanic transforms are never more than $3300 \mathrm{~m}$, it seems necessary that $c$ is less than 0.65 on slow oceanic transforms.

Thus there is both local and global evidence that coupling is typically less than unity on spreading ridges and oceanic transforms. It would be very interesting to determine what controls the locations of coupled patches within the depth range of the seismogenic lithosphere, and whether they are fixed asperities or moving instabilities in fault slip. To answer either question, we will probably need long-term ocean-bottom seismometer stations to provide more accurate earthquake locations. To determine whether the seismic patches are fixed or moving will also require the patience to wait and watch for possible repeating earthquakes.

Since coupling is typically imperfect on oceanic plateboundary faults, we should set aside the old suggestion of Solomon and Burr [1979] that oceanic plate-boundary seismicity is limited by an isothermal surface at 100$150^{\circ} \mathrm{C}$. This conclusion was always difficult to square with results of laboratory rock mechanics [e.g., Kirby, 1983] which tend to show that crust and mantle rocks of the oceanic realm will not display dislocation creep at less than about $500^{\circ} \mathrm{C}$. However, their conclusion was based on an implicit assumption of perfect coupling. If only certain patches on the fault surface are seismic, then the vertical extent of those patches may be correspondingly larger (for fixed moment production), and the limiting isotherm can be hotter. Engeln et al. [1986] and Abercrombie and Ekström [2001] each found that 600$650^{\circ} \mathrm{C}$ appears to be the rupture-limiting isotherm on Atlantic transforms, and this may be typical. We suggest that given the primitive state of current knowledge, it is more reasonable to assume a seismogenic lithosphere thickness based on laboratory flow laws, or based on these well-studied transforms in the Atlantic, and then adjust the coupling parameter to fit observed seismic moments.

Acknowledgements. Thorough and insightful reviews by Emile Okal and another reviewer were very helpful, especially in defining the form of the decline of coupled lithosphere thickness with relative velocity. Research supported by the U.S. Geological Survey (USGS), Department of the Interior, under
USDOI award number 01HQGR0021. The views and conclusions contained in this document are those of the authors and should not be interpreted as necessarily representing the official policies, either expressed or implied, of the U.S. Government.

\section{REFERENCES}

Abercrombie, R. E., and G. Ekström, Earthquake slip on oceanic transform faults, Nature (London), 410, 74-77, 2001.

Anonymous, Digital Relief of the Earth, Data Announcement, 88-MGG-02, National Oceanic and Atmospheric Administration, National Geophysical Data Center, Boulder, Colorado, CD-ROM, 1988.

Antolik, M., A. Kaverina, and D. S. Dreger, Compound rupture of the great 1998 Antarctic plate earthquake, J. Geophys. Res., 105, 23,825-23,838, 2000.

Bergman, E., and S. Solomon, Transform-fault earthquakes in the North Atlantic: Source mechanisms and depth of faulting, J. Geophys. Res., 93, 9027-9057, 1988.

Bird, P., Y. Kagan, H. Houston, and D. D. Jackson, Earthquake potential estimated from tectonic motion (abstract), EOS Trans. $A G U$, Fall Meeting Supplement, p. F1226-F1227, 2000.

Brune, J. N., Seismic moment, seismicity, and rate of slip along major fault zones, J. Geophys. Res., 73, 777-784, 1968.

Burr, N., and S. Solomon, The relationship of source parameters of oceanic transform earthquakes to plate velocity and transform length, J. Geophys. Res., 83, 1193-1205, 1978.

Cannat, M., C. Mevel, M. Maia, C. Deplus, C. Durand, P. Gente, P. Agrinier, A. Belarouchi, G. Dubuisson, E. Humler, and J. Reynolds, Thin crust, ultramafic exposures, and rugged faulting patterns at the Mid-Atlantic Ridge $\left(22^{\circ}-24^{\circ} \mathrm{N}\right)$, Geology, 23, 49-52, 1995.

Coakley, B. J., and J. R. Cochran, Gravity evidence of very thin crust at the Gakkel Ridge (Arctic Ocean), Earth Planet. Sci. Lett., 162, 81-95, 1998.

DeMets, C., R. G. Gordon, D. F. Argus, and S. Stein, Current plate motions, Geophys. J. Int., 101, 425-478, 1990.

DeMets, C., R. G. Gordon, D. F. Argus, and S. Stein, Effect of recent revisions to the geomagnetic reversal time scale on estimate of current plate motions, Geophys. Res. Lett., 21, 2191-2194, 1994.

Dziewonski, A. M., T.-A. Chou, and J. H. Woodhouse, Determination of earthquake source parameters from waveform data for studies of global and regional seismicity, J. Geophys. Res., 86, 2825-2852, 1981.

Dziewonski, A. M., G. Ekström, and N. N. Maternovskaya, Centroid moment-tensor solutions for October-December, 1998, Phys. Earth Planet. Int., 115, 1-16, 1999.

Engeln, J. F., D. A. Wiens, and S. Stein, Mechanisms and depths of Atlantic transform earthquakes, J. Geophys. Res., 91, 548577, 1986.

Escartin, J., G. Hirth, and B. Evans, Nondilatant brittle deformation of serpentines: Implications for Mohr-Coulomb 


\section{EARTHQUAKE POTENTIAL OF RIDGES AND TRANSFORMS}

theory and the strength of faults, J. Geophys. Res., 102, 28972913, 1997.

Frohlich, C., Triangle diagrams: Ternary graphs to display similarity and diversity of earthquake focal mechanisms, Phys. Earth Planet. Int., 75, 193-198, 1992.

Frohlich, C., Display and quantitative assessment of distributions of earthquake focal mechansims, Geophys. J. Int., 144, 300-308, 2001.

Frohlich, C., and K. D. Apperson, Earthquake focal mechanisms, moment tensors, and the consistency of seismic activity near plate boundaries, Tectonics, 11, 279-296, 1992.

Hanks, T. C., and H. Kanamori, A moment magnitude scale, $J$. Geophys. Res., 84, 2348-2350, 1979.

Huang, P. Y., S. C. Solomon, E. A. Bergman, and J. L. Nabalek, Focal depths and mechanisms of Mid-Atlantic Ridge earthquakes from body waveform inversion, J. Geophys. Res., 91, 579-598, 1986.

Huang, P. Y., and S. C. Solomon, Centroid depths and mechanisms of mid-ocean ridge earthquakes in the Indian Ocean, Gulf of Aden, and Red Sea, J. Geophys. Res., 92, 1361-1382, 1987.

Ihmlé, P. F., P. Harabaglia, and T. H. Jordan, Teleseismic detection of a slow precursor to the great 1989 Macquarie Ridge earthquake, Science, 261, 177-183, 1993.

Jackson, D. D., and Y. Y. Kagan, Testable earthquake forecasts for 1999, Seism. Res. Lett., 70, 393-403, 1999.

Kagan, Y. Y., Universality of the seismic moment-magnitude relation, Pure Appl. Geophys., 155, 537-573, 1999.

Kagan, Y. Y, and D. D. Jackson, Probabilistic forecasting of earthquakes, Geophys. J. Int., 143, 438-453, 2000.

Kagan, Y. Y., D. D. Jackson, Y. Rong, and P. Bird, Plate tectonics and earthquake potential on the Pacific Rim (abstract), Eos Trans. AGU, Fall Meeting Suppl., F680, 1999.

Kanamori, H., and G. S. Stewart, Mode of the strain release along the Gibbs fracture zone, Mid-Atlantic Ridge, Phys. Earth Planet. Sci., 11, 312-332, 1976.

Kirby, S. H., Rheology of the lithosphere, Rev. Geophys. Space Phys., 21, 1458-1487, 1983.

Langenhorst, A. R., and E. A. Okal, The variation of beta-values for strike-slip oceanic transform fault earthquakes (abstract), Eos Trans. AGU, Fall Meeting Suppl., F651, 1999.

Mitchell, N., J. Escartin, and S. Allerton, Detachment faults at mid-ocean ridges garner interest, Eos Trans. $A G U, 79,127$, 1998.

Mueller, D., W. R. Roest, J.-Y. Royer, L. M. Gahagan, and J. G. Sclater, Digital isochrons of the world's ocean floor, $J$. Geophys. Res., 102, 3211-3214, 1997.

Müller, C., and W. Jokat, Seismic evidence for volcanic activity discovered in central Arctic, Eos Trans. AGU, 81, 265-269, 2000.

Okal, E. A., and A. R. Langenhorst, Seismic properties of the Eltanin Transform system, South Pacific, Phys. Earth Planet. Int., 119, 185-208, 2000.

Okal, E. A., and B. A. Romanowicz, On the variation of bvalues with earthquake size, Phys. Earth Planet. Int., 87, 55$76,1994$.
Okal, E., and S. Stein, The 1942 Southwest Indian Ocean Ridge earthquake: Largest ever recorded on an oceanic transform, Geophys. Res. Lett., 14, 147-50, 1987.

Richardson, R. M., and S. C. Solomon, Apparent stress and stress drop for intraplate earthquakes and tectonic stress in the plates, Pure Appl. Geophys., 115, 317-331, 1977.

Simkin, T., and L. Siebert, Volcanoes of the World, Smithsonian Institution, Washington, D. C., 1995.

Sleep, N. H., Application of a unified rate and state friction theory to the mechanics of fault zones with strain localization, J. Geophys. Res., 102, 2875-2895, 1997.

Smith, G. P., and G. Ekström, Interpretation of earthquake epicenter and CMT centroid locations, in terms of rupture length and direction, Phys. Earth Planet. Int., 102, 123-132, 1997.

Sobolev, P. O., and D. V. Rundquist, Seismicity of oceanic and continental rifts- a geodynamic approach, Phys. Earth Planet. Int., 111, 253-266, 1999.

Solomon, S. C., Sizes of ridge crest earthquakes and lithospheric thickness at spreading centers (abstract), Eos Trans. AGU, 57, 954, 1976.

Solomon, S. C., and N. C. Burr, The relationship of source parameters of ridge-crest and transform earthquakes to the thermal structure of oceanic lithosphere, in: Francheteau, J. , editor, Processes at Mid-Ocean Ridges, Tectonophysics, 55, 107-126, 1979.

Solomon, S. C., P. Y. Huang, and L. Meinke, The seismic moment budget of slowly spreading ridges, Nature, 334, 58-60, 1988.

Tucholke, B. E., and J. Lin, A geological model for the structure of ridge segments in slow spreading oceanic crust, J. Geophys. Res., 99, 11,937-11,958, 1994.

Watanabe, T., S. Kodaira, H. Shiobara, T. Kanazawa, R. Stefansson. G. B. Gudmundsson, and H. Shimamura, Microseismicity in the Reykjanes Ridge, July 1990: Hypocenter distribution derived from an OBS array, Zisin, ser. 2, 45, 327337, 1992.

Yeats, R. S., K. Sieh, and C. R. Allen, The Geology of Earthquakes, Oxford University Press, New York, 568 pages, 1997.

Zoback, M. L., First- and second-order patterns of stress in the lithosphere: The World Stress Map project, J. Geophys. Res., 97, 11,703-11,728, 1992.

Department of Earth and Space Sciences, University of California, Los Angeles, CA 90095-1567 